\title{
AS PEREGRINAÇÕES COMO ATRAÇÕES TURÍSTICAS
}

- SANDRA DE SÁ CARNEIRO

RESUMO: 0 PROPÓSITO DESTE ARTIGO É APRESENTAR UMA REFLEXÃO A RESPEITO DAS MÚLTIPLAS INTERFACES ENTRE AS PEREGRINAÇ̃̃es E 0 FENÔMENO dO TURISMO. A PARTIR DA ANÁLISE DE DISTINTAS PEREGRINAÇ̃̃ES NO BRASIL E NO MUNDO, BUSCA-SE COMPREENDER COMO OS CAMINHOS RELIGIOSOS VEM SENDO RESSIGNIFICADOS DE FORMA A ASSUMIR UM SENTIDO MUITO APROXIMADO DE ATRAÇ̃̃O TURISSTICA.

PALAVRAS-CHAVE: RELIGIÕES. PEREGRINAÇ̃̃ES. TURISMO

Nos últimos anos tenho me dedicado ao estudo das relações complexas entre religião/modernidade, peregrinação/ turismo. Nesse artigo ${ }^{1}$ apresento algumas reflexões sobre as múltiplas interfaces entre peregrinação e turismo, procurando discutir como a primeira vem sendo ressignificada e, em alguns contextos, pode assumir um sentido muito próximo ao de atração turística. Tomo como base dados coletados nos estudos de casos empíricos de peregrinações que investiguei em diferentes momentos. Seja no contexto da pesquisa que desenvolvi em meu doutorado, que tinha como objeto empírico a peregrinação ao Caminho de Santiago de Compostela, na Espanha (CARNEIRO, 2003 e 2007), ou, no contexto de outro projeto que teve como foco as novas peregrinações inspiradas no Caminho de Santiago que surgiram no Brasil a partir do final dos anos 90, envolvendo prefeituras, Igreja Católica, agências de turismo e organizações da sociedade civil, especialmente as Associações dos Amigos do Caminho de Santiago. Nesse estudo 2, que chamamos de "Caminhos de Santiago no Brasil", procuramos focalizar elementos de diferentes tradições religiosas e de campos diversos de práticas, que Frey (1999) 
descreve na sua etnografia sobre peregrinos na Espanha e que eu também pude perceber no contexto brasileiro (CARNEIRO, 2004 e 2007).

$\mathrm{Na}$ pesquisa sobre a peregrinação a Santiago de Compostela (que surgiu na Idade Média) eu já tinha tido a oportunidade de destacar a sua ampla visibilidade e difusão em solo brasileiro, principalmente com a publicação de mais de sessenta livros escritos sobre o assunto, da criação de várias associações por todo o país e da produção de vários sites, blogs e vídeos, disponibilizados em uma ampla rede de divulgação. Calcula-se que nos últimos quinze anos mais de vinte mil brasileiros realizaram essa peregrinação (uma ou mais vezes), sendo que, em 2001, o Brasil foi o terceiro país estrangeiro que contou com o maior número de peregrinos que recebeu a Compostela ${ }^{3}$. Foi justamente o expressivo crescimento do número de peregrinos brasileiros que se dirigiam a Santiago um dos motivos que me levou a iniciar minha pesquisa sobre esse assunto.

Ao lado disso, na esteira do amplo processo de revitalização dessa peregrinação e do seu impacto em solo brasileiro, foram criadas aqui cinco novas rotas de peregrinação: Caminho da Luz (Minas Gerais), Caminho do Sol (São Paulo), Passos de Anchieta (Espírito Santo), Caminho da Fé (Minas Gerais e São Paulo) e Caminho das Missões (Rio Grande do Sul).

Assim, logo depois de terminar a tese de doutorado passei a me dedicar ao estudo dessas novas rotas (CARNEIRO, 2004; STEIL e CARNEIRO, 2011).
Para entendermos a construção social desses fenômenos é preciso focalizar as interfaces entre significados que emergem tanto no campo da religião quanto do turismo (STEIL, 2003). Entendo assim as peregrinações modernas como contextos sociais em questão revelados elementos que possibilitam a reflexão sobre tendências presentes na sociedade contemporânea. Nessa medida, o estudo interpretativo em tal campo permite a identificação e compreensão de processos que marcam um contexto social mais amplo.

A perspectiva que venho adotando é a de valorizar as experiências sociais e subjetivas do deslocamento e os significados que são atribuídos a essas experiências. Ao analisar essas relações, tenho procurado destacar os pontos de contato, as tensões, as negociações e as possibilidades de se potencializarem mutuamente.

Outro aspecto importante tem sido o de investigar o papel de mediação que as prefeituras, as secretarias municipais de turismo e cultura e as agências de turismo vem desempenhando nessas peregrinações, em detrimento do papel da Igreja Católica antes hegemônico.

Em suma, busco compreender como determinados caminhos de peregrinação são construídos, assumem formas e significados distintos e incorporam novos mediadores.

Um dos enfoques interpretativos que venho adotando em meus estudos sobre as "modernas peregrinações" tem como inspiração as colocações de Eade e Sallnow (1991) sobre o caráter multidimensional e pluralístico do 
fenômeno. Fazer o Caminho de Santiago ou qualquer outro caminho de peregrinação não é uma experiência da qual brota por si mesmo um significado unívoco, autônomo e plenamente constituído e sim, se constitui e se elabora a partir de diferentes universos de significado que na maior parte dos casos estão imbricados.

Cabe ainda lembrar que essas práticas de peregrinação integram processos mais gerais de mudanças que atravessam a sociedade, por isso, a chave de leitura que tem me interessado para compreendê-los é o ponto de vista dos indivíduos. Por isso, busco compreender as suas percepções do local, da paisagem, da mobilidade.

\section{Caminhos e peregrinações: situações plurais}

Um dos aspectos que mais me chamou a atenção quando comecei a investigar este assunto era a maneira pela qual esses caminhos eram apresentados e veiculados nos sites oficiais, nos jornais de grande circulação e na televisão. As narrativas através das quais eles eram descritos já sinalizava para o processo de transformação e mudança do que tradicionalmente se entende por peregrinação. Através das apresentações dos sites podemos perceber as diversas dimensões que comportam estes fenômenos e de suas múltiplas interfaces, conforme os exemplos a seguir:

O Caminho das Missões é um roteiro de caminhadas pelas antigas estradas missioneiras que ligavam as Reduções Jesuítico-Guarani. O trajeto segue pelo município de Garruchos que possui uma natureza exuberante. Ao longo do trajeto estão três Patrimônios Nacionais: os sítios arqueológicos de São Nicolau (no município de São Nicolau), São Lourenço (em São Luiz Gonzaga) e São João Batista (em Entre-ljuis), e um Patrimônio da Humanidade, as ruínas da missão de São Miguel Arcanjo no município de São Miguel das Missões. O caminho se apresenta como uma jornada, seja de peregrinação mística, tradição, lazer, pesquisa ou esporte.

O Caminho da Luz é uma rota de peregrinação. Caminho de peregrinação religiosa, ecológica e histórica. Tem início em Tombos (Portal de Minas), onde está situada a quinta maior cachoeira em volume de queda d'água do país, e é concluído no Pico da Bandeira, o terceiro mais alto do país e o primeiro mais alto acessível. O Caminho leva à introspecção. Introspecção que nos conduz a um maior conhecimento de nós mesmos, de nossos defeitos e virtudes e da nossa pequenez diante do Criador, dando-nos a certeza de que, quanto mais temos, mais sofremos, mas também a certeza de que, quanto mais caminhamos em direção à luz, mais nos aproximamos de Deus.

Os Passos de Anchieta é o nome do roteiro que reconstitui a trilha habitualmente percorrida pelo Padre Anchieta. O roteiro resgata o trecho de 100 quilômetros compreendidos entre Anchieta e Vitória que José de Anchieta percorria regularmente duas vezes por mês, o denominado "caminho das 14 léguas". A experiência da caminhada combina encantos como o 
conhecimento de sítios históricos, com paisagens que se oferecem ao andarilho numa sequência de belos quadros da natureza de uma região que é um marco geográfico da costa brasileira, onde as culturas do norte e do sul do país se encontram. O que se sobressai acima da gratificação cultural ou do fervor religioso ou da fruição de cenários atraentes é uma singular experiência de introspecção que na prática constitui a alma de todos os caminhos místicos. A reflexão inevitável que uma longa caminhada proporciona enseja insights marcantes. Não por acaso a caminhada é uma adequada metáfora do viver.

O Caminho do Sol nasceu com o objetivo maior de oferecer aos amantes de caminhadas, um ambiente agradável, passando em sua quase totalidade, somente por áreas rurais, buscando a introspecção e o despojamento material.

Como podemos perceber, nessas distintas narrativas as peregrinações são descritas como experiências que podem proporcionar aos peregrinos: "conhecimento de si mesmo", "introspecção", "despojamento material" em uma dimensão mais subjetiva. Mas também podem favorecer o contato dos peregrinos com "paisagens", com uma "natureza exuberante" e com "belos quadros da natureza". Além disso, valoriza-se a possibilidade de se conhecer durante o percurso "patrimônios nacionais", "sítios históricos e arqueológicos", ruínas, etc. Ao mesmo tempo aponta-se para uma dimensão da experiência de se realizar esses caminhos que pode significar também uma peregrinação "mística" ou "religiosa", através da qual podemos ter uma "aproximação de Deus", contato com o "Criador" e "fervor religioso". Seguindo ainda a polissemia dos sentidos, a experiência de peregrinação pode conjugar também lazer, esporte e ecologia, sendo que estes "atributos" ou "atrativos" não são excludentes, mas combinam-se de acordo com a interpretação muitas vezes construída pelos idealizadores dessas rotas, servindo de suporte para suas distintas imagens e representações.

Todo esse repertório para definir as rotas estudadas configura um marco teórico e interpretativo muito sugestivo para a sociedade atual, plural e secularizada. Um marco que libera a peregrinação dos seus referentes estritamente cristãos e católicos e associa a experiência do peregrino não só a um momento de ruptura com o cotidiano, em uma situação que também pode ser de ócio, mas também a um tipo de espiritualidade que se aproxima daquela que vem sendo definida como Nova Era, permitindo uma reinterpretação livre e polissêmica de sua linguagem simbólica e ritual.

O marco de sentidos expresso nas imagens dos sites converte os caminhos brasileiros em uma meta muito atrativa tanto para peregrinos como para turistas. Por isso, o objetivo de compreender a forma que adota estas novas peregrinações requer novas categorias que ultrapassam os limites da diferenciação estrita entre turismo e peregrinação.

A realização dessas peregrinações nos sugere que elas representam hoje em dia uma resposta à crescente demanda turística centrada 
em elementos da cultura como imagens, símbolos e componentes estéticos geradores de experiências e sentimentos. A secularização da sociedade e a perda da centralidade da Igreja Católica permitem que essas imagens e esses símbolos sejam tomados de rituais religiosos e que, liberados do controle da instituição eclesial, se articulem de maneiras diversas dando lugar a formas sincréticas (HERRERO, 2009).

Ao lado disso, através das entrevistas que realizei com peregrinos, bem como dos depoimentos disponibilizados nos sites oficiais dos caminhos espanhol e brasileiros, pude perceber que os indivíduos interpretam os mesmos fatos a partir de marcos de significados muito diferentes, desde leituras prévias ou posteriores, desde conversas e trocas com outros peregrinos, desde experiências vitais, crenças etc. Trata-se assim de considerar a essencial heterogeneidade do processo de peregrinação suprimido ou negado por outras perspectivas analíticas. Portanto, adoto como perspectiva analítica aquela que entende a peregrinação como lugar de encontro e muitas vezes de competição de discursos religiosos e seculares (EADE e SALLNOW, 1991). O enfoque multidimensional proposto por estes autores implica uma mudança na compreensão do sagrado e da peregrinação. Realizar esses caminhos não é uma experiência que tem um significado unívoco, autônomo e plenamente constituído, e sim que se constitui como projeção, convergência e elaboração a partir de diferentes universos de significado.
"As motivações para se fazer o Caminho são as mais diversas: há os que o fazem por motivos religiosos, outros para terem chance de uma introspecção e também aqueles que desejam encarar o desafio físico e psicológico de uma caminhada, que era mais o meu caso. Porém, uma coisa é certa: quando você inicia o Caminho, por mais que tenha ideia do que procura, do que pretende encontrar, do que pretende aprender, está longe, mas bem longe mesmo de imaginar tudo o que acontecerá com você ao terminá-lo." (Peregrino do Caminho do Sol).

As Associações de Amigos dos Caminhos também são fundamentais na divulgação de sistemas de ideias e padrões de comportamento através dos sites, livros, boletins, enfim, de toda uma complexa rede informativa. É possível perceber que em geral, as associações apostam na ideia da possibilidade de "mudança interior", associada ao processo de vivências e experiências que se pode ter durante a realização do caminho, quando os peregrinos são confrontados com desafios físicos e mentais.

Além dessas questões, é comum os peregrinos se referirem à prática da solidariedade e da comunhão com o próximo que experimentam e que deixam de ser figuras de retórica. Durante o percurso, 
desenvolvem amizades ou mesmo disputas entre pessoas que em outras circunstâncias não seria possível serem realizadas. Lembro-me do depoimento de duas irmãs que, sempre tendo sido muito amigas e unidas, fizeram o Caminho de Santiago. Durante o percurso conseguiram, pela primeira vez, trazer à tona todas as mágoas e divergências que sempre existiram, mas que estavam, segundo elas, "adormecidas". Uma delas chegou a afirmar que por pouco não bateu em sua irmã com o cajado em uma das muitas brigas que tiveram durante a peregrinação.

Os depoimentos ou as narrativas dos peregrinos estão repletos de referências a sentimentos suscitados pelas trocas durante o percurso. Segundo grande parte dos peregrinos, nenhuma outra experiência lhes proporcionou essa magnitude de viver ali sentimentos de conflitos, irritação ou discórdia, mas também lições de fraternidade, generosidade, gratuidade e, principalmente, de relações solidárias.

No site do Passos de Anchieta é reforçado que "no começo de uma caminhada o corpo enfrenta um breve desconforto pelo rompimento da inércia. Logo ele estará liberando hormônios como endorfinas, beta endorfinas e serotoninas que são considerados os "elixires da felicidade". Elevam o ânimo e o entusiasmo ("Deus dentro de si") e aí, para muitos peregrinos, estaria a maior gratificação da caminhada, mais que a contemplação da natureza. Por isso, é importante entender como o "corpo" fisiológico pode ser pensado como uma categoria analítica nestes contextos.

\section{Corpo, self e ecologia}

Algumas das proposições de Csordas (2002) têm me auxiliado bastante na compreensão das peregrinações modernas. Particularmente quando ele sugere que devemos entender o corpo não apenas em sua dimensão biológica, mas igualmente religiosa, linguística, histórica, cognitiva, emocional e artística, que a linguagem pode ser apresentada como uma expressão da corporeidade (embodiment) e que a noção de cultura precisa ser redimensionada. Não se trata apenas de definir esta última em termos de símbolos, esquemas, regras, costumes, textos ou comunicação, mas também em termos de sentido, movimento, intersubjetividade, hábito, desejo, evocação e intuição. A convergência dessas duas realizações leva à conceitualização do self baseado na corporeidade (embodiment). $\mathrm{O}$ argumento principal é que, pelo colapso da distinção entre corpo emente, sujeito e objeto, a linguagem se torna compreensível tal como um processo do self quando ela é vista não como uma representação, mas como instituição de um modo de ser no mundo (CSORDAS, 2002, p.4).

Dessa forma, tenho estado atenta para perceber e valorizar a pluralidade das experiências e narrativas dos peregrinos que se entrelaçam e busco também problematizar a "invenção" dos caminhos estudados que se constituem como rotas de valor cultural, econômico e político.

Entendo que esses caminhos em sua versão contemporânea e também brasileira apontam para outro modelo de peregrinação que está fortemente 
associado ao fenômeno do turismo e a uma nova modalidade de espiritualidade que muitos autores denominam de religiões do self. Segundo esse modelo, empreender uma jornada de longa distância, que envolve determinação, persistência, humildade e austeridade, é percebido menos em um sentido de sacrifício e mais como um processo de "descoberta de si mesmo" e de contato com o passado, presente na paisagem do caminho e nos símbolos que vão sendo acessados ao longo do percurso.

A emergência dessa modalidade de peregrinação que se constitui também como uma atração turística acaba por ressignificar as antigas peregrinações que, embora mantenham um formato tradicional, deixam-se pouco a pouco penetrar por valores e motivações mais próximos daquilo que vem sendo chamado de movimento da Nova Era. Trata-se de um modelo que enfatiza mais a própria caminhada, o próprio percurso, em contraposição ao lugar de chegada ou ao objeto de devoção, como seria o caso da peregrinação "tradicional". Ao se deslocarem, os peregrinos modernos acabam por atribuir um sentido central à forma como se engajam pessoal e corporalmente à experiência. Portanto, ganha centralidade a forma pela qual o indivíduo empreende a viagem, sendo a realização a pé a forma mais valorizada, mais próxima ao que muitos peregrinos chamam de "autêntica peregrinação". Desse modo, a distinção entre peregrinos com ou sem motivação religiosa perde a sua importância em prol da valorização da experiência de caminhar e do aprendizado advindo daí.
"O que leva uma pessoa transformar suas férias em desafios? Deixando o conforto, família, amigos para fazer o caminho? Busca de Aventura! Desafios! Autoconhecimento! Não importa os motivos. O que sei, é que qualquer que seja ele, o caminho do sol te proporciona e muito mais, dependendo unicamente de você."

Outro aspecto importante é a ideia de que a experiência do peregrino está informada pela cultura (Turner, 1978), ou seja, é informada por normas, valores, significados que não são exclusivamente individuais e próprios, pois são culturais. Enquanto no sistema da peregrinação tradicional o sacrifício tem um significado predominante, é uma forma de penitência orientada por aquilo que Turner (1978) chama de "paradigma da via crucis", nas novas rotas pode-se até mesmo valorizar o esforço físico e o sacrifício corporal que comporta a peregrinação a pé, mas a questão de fundo é a "metáfora do viver". Caminha-se para romper com o cotidiano, para ter momentos de "introspecção" e de maior possibilidade de reflexão sobre as próprias vidas.

"Senti que necessitava de mudança em meu estilo de vida e começar a fazer coisas que fossem hesitantes demais para tentar. Vivia em circunstâncias infelizes, mas não tomava a iniciativa de mudar a situação 
porque estava condicionado a uma vida de conformismo e segurança.

Tudo isso parecia me deixar em paz, mas na verdade não existe coisa pior para o espírito aventureiro de um homem que um futuro seguro. Então larguei tudo para viver um momento sabático e para começar resolvi fazer o caminho do sol, onde nem imaginava o que poderia acontecer e o que estava por vir. Como nada nesta vida é por acaso, Deus me colocou naquela peregrinação para começar com o pé direito o meu momento." (peregrino do caminho das Missões)

Entendo também que esses caminhos ou peregrinações dialogam com as condições e as paisagens culturais que os definem, abrindo outro horizonte possível de experimentação e compreensão do mundo. Nesse sentido, sustento, seguindo o viés interpretativo proposto por Ingold (2000), que tanto o conceito de peregrinação precisa ser compreendido a partir do ponto de vista do peregrino, como o conceito de deslocamento no âmbito do secular deve ser percebido através da relação que os peregrinos mantêm com essa esfera assim considerada. Dentro dessa perspectiva, a própria noção de viagem e de deslocamento está em discussão. Sendo que essas categorias podem adquirir também um sentido alegórico - interior, espiritual - ao invés de corresponderem a um sentido puramente empírico, aquele do "deslocamento geográfico" (INGOLD, 2000).

Deslocamentos de sentidos subjetivos, identitários e espaciais tem sido tematizado por diversos autores como Bauman (1996, 1998) e Clifford (1997) que se referem à peregrinação como metáfora para os tempos contemporâneos. Já outros como Simon Coleman \& John Eade (2004) ampliaram o sentido do termo, descentraram a análise da peregrinação do santuário e desvincularam a relação supostamente necessária entre deslocamento e espaço. Contudo, preservaram a ideia de movimento e incluíram, ao lado do espacial, outras formas de deslocamentos corporificados (embodied) - imaginados e metafóricos

Um aspecto importante é a ênfase dada à ecologia em algumas dessas peregrinações, particularmente aos valores ambientais, relacionados com a preservação da natureza. Tanto nas apresentações dos caminhos já indicados anteriormente como nos depoimentos dos peregrinos emerge recorrentemente a importância concedida à experiência de contemplação da natureza como paisagem. Essa contemplação ofereceria uma possibilidade de ruptura com o mundo do trabalho, com o cotidiano, marcado pela ideia de tumulto da vida na cidade. Neste caso, é possível perceber as analogias que os peregrinos fazem entre os valores ditos ecológicos e a chamada "espiritualidade" Nova Era. 
De fato, os sentidos atribuídos às peregrinações parecem fomentar e potencializar a experiência religiosa individual, isto é, do próprio sujeito, sem mediação institucional. $\mathrm{O}$ deslocamento nesse "tipo" ou modalidade de peregrinação tende a assumir um contorno "espiritual" e um significado de transformação do self que, por vezes, se sobrepõe às razões formuladas para a criação do Caminho.

Isso pode ser exemplificado pelo caso do Caminho Passos de Anchieta, cuja fundação mítica atribui ao padre Anchieta o papel de peregrino exemplar. $\mathrm{O}$ ato de se deslocar e de se misturar com a paisagem vem compor, em consequência, essa experiência do sagrado. Caminhar pelas praias contemplando a natureza, pisar descalço na areia, sentir o vento penetrando no corpo fazem parte dessa sacralização do deslocamento.

\section{Caminhos como revitalizadores das economias regionais e/ou periféricas}

\footnotetext{
Algumas rotas são apresentadas como tendo também por objetivo proporcionar à localidade, à região ou aos municípios por elas atravessados uma alternativa econômica/turística ou mesmo uma revitalização do turismo local. Grande parte dos municípios atravessados por esses caminhos apostaram em suas criações em função dos benefícios que eles podiam trazer para a economia local. Em geral, são localidades que sofreram forte declínio econômico e com a "invenção" das rotas passaram por um processo de ressignificação e puderam ser "colocados no
}

mercado" como verdadeiros locais "bucólicos", "onde se vive a autentica vida das fazendas ou no campo", "onde o clima é o melhor do estado", etc.

Em todas as rotas estudadas percebe-se uma grande valorização dos patrimônios locais como atrativos turísticos. Os patrimônios locais abarcam a casa onde nasceu Tarsila do Amaral (Caminho do Sol), as ruínas das Missões Jesuíticas (como a de Santo Ângelo ou São Miguel) e até mesmo as praias atravessadas pelo Passos de Anchieta ou a visita à Igreja N. S. da Penha. Normalmente, os peregrinos são estimulados a visitarem as igrejas, museus, fazendas, monumentos locais em cada localidade que atravessam.

Argumentando a favor do enfoque que valoriza a pluralidade das experiências e narrativas que se entrelaçam, fazendo dos contextos turístico-religiosos situações irremediavelmente plurais, procuro problematizar as ressignificações que o fenômeno das peregrinações parece ganhar na contemporaneidade. Destaco os distintos sentidos que elas podem comportar tanto para os novos mediadores - os idealizadores dessas rotas (na maioria dos casos são ex-peregrinos do caminho de Santiago), os agentes de turismo, as prefeituras, quanto para os peregrinos. Em certa medida, algumas priorizam o aspecto religioso, outras, o aspecto ecológico, o ambiente, a natureza. Mas o certo é que nenhuma delas apresenta apenas uma única dimensão como "atrativo". Isso parece indicar que, independentemente do motivo que possa levar 
uma pessoa a realizar uma dessas peregrinações, o simples fato de ter uma experiência de caminhar já é apresentado muitas vezes como uma "experiência significativa, poderosa".

Ao analisar as relações entre peregrinação e turismo nesses contextos, tenho procurado enfatizar os pontos de contato, as tensões, as negociações e as possibilidades de se potencializarem a mediação das prefeituras e do mercado através do envolvimento das secretarias municipais de turismo e cultura e das agências de turismo. A meta tem sido perceber as interseções múltiplas, os pontos convergentes e divergentes que o sentido de viajar tem adquirido no horizonte das transformações recentes do campo religioso e do campo turístico.

Em certa medida o que se apresenta como recorrente é a ênfase no trajeto, o próprio percurso, em contraposição ao lugar de chegada, seja a basílica de Aparecida do Norte, como no caso do Caminho da Fé, seja o horto florestal com as imagens de Santiago e São Francisco (Caminho do Sol) ou o Pico da Bandeira (Caminho da Luz).

Compreende-se que ao fazer tal deslocamento acaba-se atribuindo um sentido central à forma como o caminhante se engaja pessoal e corporalmente à experiência. Portanto, a forma pela qual o peregrino empreende a viagem - a pé, de bicicleta, de carro, de ônibus de excursão etc. é que passa a contar realmente para a definição da "autêntica peregrinação". Desse modo, a distinção entre caminhantes religiosos e não-religiosos parece se diluir em prol da importância que ganham as experiências do caminhar e do seu aprendizado.

A ideia de que o turismo moderno pode ser visto como uma continuação das peregrinações tradicionais, na medida em que condensa sentidos e valores em outros momentos vinculados a essa experiência religiosa, já foi sugerido por Dean Mac Cannell (1976). Proposição semelhante foi elaborada por Cohen (1979), ao efetuar uma análise do turismo a partir da ênfase na experiência do distanciamento do cotidiano. Ambos os fenômenos, sugere o autor, estão diretamente associados aos tempos e espaços não cotidianos e podem ser entendidos como respostas à busca de novas referências identitárias no contexto de fragmentação e multiplicidade de estilos de vida que caracterizam a sociabilidade contemporânea. Enquanto formas de deslocamento espacial, peregrinações e turismo se apresentariam, ainda, como categorias de compreensão da realidade que condensam estruturas de significados permanentemente atualizadas e reavaliadas (STEIL, 2003 e CARNEIRO, 2003).

Trata-se de uma modalidade de deslocamento que nos leva a redimensionar os sentidos das peregrinações "tradicionais", cujo sentido fundamental estava normalmente associado a ir "em direção a um lugar sagrado" ou à "busca do sagrado". As modernas peregrinações surgem com vigor, assumindo novos formatos e incorporando novos mediadores.

\section{Considerações finais}


Em termos analíticos, entendo essas peregrinações modernas menos como discurso e representação, e mais como algo que é vivido e experimentado, e, sobretudo, expresso material e afetivamente (embodied na paisagem e no corpo) (COLEMAN, 2002; COLEMAN e EADE 2004). Assim, para além de um processo de desterritorialização, podem ocorrer efeitos de deslocamentos de sentido e significação de acordo como o acervo simbólico que é acionado pelos diversos atores sociais que estão envolvidos na consecução destas peregrinações.

Portanto, as "experiências do caminhar" que tenho valorizado em minhas pesquisas possibilitam analisar as formas através das quais esses caminhos e/ou peregrinações, ao serem realizados pelos sujeitos, absorvem das paisagens culturais e sociais que atravessam.

É importante lembrar que a categoria deslocamento guarda aqui um sentido ambíguo fim de preservar as diferentes dimensões da realidade social que pode representar. Essa categoria, em sua acepção mais comum, se refere ao fenômeno empírico do deslocamento de pessoas e/ou tradições culturais através de espaços. Mas, podemos também nos referir aos deslocamentos privilegiando os sentidos, subjetivos, identitários e espaciais como importantes para a nossa análise.

Devo lembrar ainda que a simples definição de deslocamento tem provocado debates importantes no campo antropológico. Muitos autores enfatizam os aspectos da desterritorialização, fluidez e hibridização
(APPADURAI, 1998; BHABHA， 2003; CANCLINI, 1997). Outros chamam a atenção para fenômenos que envolvem processos contrários aos anteriores, como fixação e territorialização produzidos e mediados por sistemas de reciprocidade enraizados localmente (SAHLINS, 1997). Outra linha interpretativa enfatiza o enraizamento da tradição no lugar e é mais reticente quanto à ideia de tradição separada de espaço, fazendo uma crítica contundente à noção genealógica de tradição (herança/conhecimento cognitivo e simbólico).

Finalizando, quero sugerir que esses caminhos ou peregrinações interagem também com as condições e as paisagens culturais que os definem, abrindo outro horizonte possível de experimentação e compreensão do mundo. Dessa forma, tanto o conceito nativo de peregrinação no plano religioso precisa ser compreendido a partir do ponto de vista do peregrino, como o conceito de viagem no plano secular deve ser percebido através da relação que os peregrinos mantêm com esta esfera assim considerada. Além disso, entendo, seguindo Ingold (2000), que as categorias de viagem e deslocamento podem adquirir também um sentido alegórico - interior espiritual - ao invés de corresponderem a um sentido estritamente empírico, aquele do "deslocamento geográfico".

Outra ponderação importante diz respeito às formas atuais que adotam essas peregrinações por intermédio da intervenção de agentes 
seculares que potencializam e difundem esses significados e os institucionalizam.

Meu interesse em estudar rotas de peregrinação está centrado nos motivos renovados que hoje são capazes de impulsionar os peregrinos a terem esse tipo de experiência e nos sentidos que lhes são atribuídos. Entendo que tais motivos e interpretações exprimem características próprias das sociedades contemporâneas, mais secularizadas, onde não só a religião, mas também as peregrinações sofrem um processo de ressignificação. Por outro lado, partilho da ideia desenvolvida por Hobsbawn e Ranger (1997) de que as tradições são inventadas, ou seja, são sempre recriações, uma representação do passado que se realiza em função dos interesses e necessidades do presente. Do ponto de vista antropológico, me interessa então desvendar como se produzem essas recriações, que atores e grupos sociais intervêm nelas e de que maneira.

No caso específico das peregrinações, podemos dizer que uma das forças fundamentais que influencia fortemente na recriação das tradições é o turismo. Fenômeno que hoje não está somente impulsionado pelos interesses empresariais, mas também pelas administrações públicas que veem nele uma saída para a crise econômica dos municípios e governos. No caso do Caminho de Santiago, na esteira de seu processo de revitalização e da situação crítica ocasionada pela unificação européia nos setores produtivos tradicionais das regiões periféricas da Europa como é o caso da Galícia.

No caso das rotas brasileiras, investe-se em seu potencial para fomentar o desenvolvimento econômico e político de regiões igualmente periféricas, daí a participação maciça das prefeituras na construção dessas rotas. Se antes havia uma crítica ferrenha por parte dos estudiosos sobre os efeitos malévolos do turismo nas comunidades receptoras, hoje já se fala em um turismo "cultural", que supõe, entre outros efeitos, uma alternativa econômica para as localidades receptoras. A ideia do turismo como forma de colonialismo ou imperialismo tem sido bastante relativizada hoje em dia, uma vez que, além de significar uma alternativa econômica, o turismo também pode ser percebido pelos efeitos de dinamização que provoca na cultura e identidade local. Chega muitas vezes a impulsionar a recuperação de tradições esquecidas e a sua revalorização por parte dos próprios "anfitriões".

\section{NOTAS}

${ }^{1}$ Uma primeira versão desse artigo foi apresentada sob forma de comunicação durante a VIII Reunião de Antropologia do MERCOSUL (RAM), realizada em Buenos Aires, Argentina, em 2009

\footnotetext{
${ }^{2}$ Esse estudo foi realizado sob a coordenação de Carlos Alberto Steil (UFRGS)

${ }^{3}$ Certificado expedido pela Catedral de Santiago de Compostela, espécie de diploma escrito em latim, concedido pelo arcebispo de Santiago a todos aqueles que tenham percorrido pelo menos $100 \mathrm{~km}$ a pé ou a cavalo ou $200 \mathrm{~km}$ de bicicleta, atestados através da credencial do peregrino, que indica os locais percorridos.
} 
REFERÊNCIAS BIBLIOGRÁFICAS

APPADURAI, Arjun. Disjunção e diferença na economia cultural global. In: FEATHERSTONE, Mike (org.) Cultura Global: Nacionalismo, Globalização e Modernidade. Rio de Janeiro: Vozes, 1998.

BHABHA, Homi. O Local da Cultura. Belo Horizonte: Editora UFMG, 2003

BAUMAN, Zigmunt. From pilgrim to tourist or a short history of identity. In: HALL, Stuart \& GAY, Paul (lorgt). Question of Cultural Identity. Britain: The Cromwell Press, 1996. O Mal-Estar da Pós-Modernidade. Rio de Janeiro: Zahar, 1998.

CANCLINI, Néstor Garcia. Culturas híbridas: estratégias para entrar e sair da modernidade. São Paulo: Edusp, 1997.

CARNEIRO, Sandra de Sá. Rumo a Santiago de Compostela: os sentidos de

uma moderna peregrinação. Tese (Doutorado em Antropologia Social). Rio de Janeiro:

PPGSA/IFCS/UFRJ, 2003 a.

Caminho de Santiago de Compostela: percurso, identidade e passagens. In: BIRMAN, Patrícia. (org.). Religião e Espaço Público. São Paulo: Attar, 2003b.

Novas peregrinações brasileiras e suas interfaces com o turismo. Ciências Sociales e Religion. n. 6, ano 6, 2004

Paulo: Attar, 2007

A Pé e com Fé: brasileiros no Caminho de Santiago. São

CLIFFORD, James. Routes: Travel and Translation in Late Twentieth Century. Harvard University Press, 1997.

COHEN, Erik. A phenomenology of tourist type". Sociology, n. 13 p.179-201, 1979

COLEMAN, Simon. Do you believe in pilgrimage? Communitas, contestation and beyond. Anthropological Theory.Vol.2 (3), 2002 EADE, John. Introduction: reframing Pilgrimage. In: Reframing Pilgrimage: Cultures in Motion. London; New York: Routledge, 2004.
CSORDAS, Thomas. Introduction: the body as representation and being-in the

world. In: CSORDAS, Thomas (org.). Embodiment and Experience: the existential

ground of culture and self. Cambridge: Cambridge University Press, $1994 a$

EADE, John; SALLNOW, Michael. Contesting the sacred. The Anthropology of pilgrimage. London/New York: Routledge, 1991.

GRABURN, Nelson. The sacred journey. In: SMITH, Valene (org.).

Hosts

and Guests: the Anthropology of Tourism. Philadelphia: University of

Pennsylvania

Press, 1977

$\overline{\text { Anfitriones }}$ Turismo: El Viaje Sagrado. In: SMITH, Valene (org.).

e Invitados. Madrid: Endymión, 1992.

HELAS, Paul. A Nova Era no Contexto Cultural: Pré-Moderno, moderno e pós-moderno. Religião e Sociedade, 17(1-2), Rio de Janeiro:ISER, 1996

HERRERO, Nieves. A interpretación do Camiño de Santiago en Clave Celta. A sua presencia na peregrinación actual. Actas II Congreso Transfronteiriço da cultura celta. Ponte de Baza, 2009. HOBSBAWN, E. \&RANGER, T. A invenção das tradições. Rio de Janeiro: Paz e Terra, 1997.

INGOLD, Tim. The Perception of the Environment. Essays in Livelihood, Dwelling and Skill. London; New York: Routledge, 2000.

MACCANELL, Dean. The Tourist: A New Theory of the Leisure Class. New

York: Schocken, 1976

SAHLINS, Marshall. O pessimismo sentimental e a experiência etnográfica porque a cultura não é um objeto em vias de extinção. Parte I e II. Mana, v.3, no.1, 1997.

STEIL, Carlos Alberto. Peregrinação, Romaria e Turismo religioso: raízes etimológicas e interpretações sociológicas. In: Edin Sued Abumanssur (org.). Turismo Religioso: ensaios antropológicos sobre religião e turismo. Campinas: Papirus, 2003.

TURNER, Victor. O Processo Ritual: estrutura e antiestrutura. Petrópolis: Vozes, 1974.

TURNER, Victor; TURNER, Edith. Image and Pilgrimage in Christian Culture. New York: Columbia University Press, 1978.

THE PILMIGRAGES AS TOURIST ATRACTION

ABSTRACT: THE AIM OF THIS ARTICLE IS TO PRESENT A DISCUSSION ON THE MULTIPLE INTERFACES BETWEEN PILGRIMAGE AND TOURISM PHENOMENON. TAKING INTO ACCOUNT DIFFERENT EXAMPLES ON PILGRIMAGE IN BRAZIL AND AROUND THE WORLD, THE GOAL IS TO UNDERSTAND HOW THE RELIGIOUS PATHS HAVE BEEN RE-SIGNIFIED IN ORDER TO BECOME A TOURIST ATTRACTION. 
KEYWORD: RELIGIONS - PILGRIMAGES - TOURISM

ESPAÇO E CULTURA, UERJ, RJ, N. 31, P.66-79, JAN./JUN. DE 2012

http://www.e-publicacoes.uerj.br/index.php/espacoecultura/ 